\title{
Long-Term Treatment of Early Childhood Caries (ECC)
}

\author{
Bahram Ghassemi $^{1 *}$, Maryam Maghsoudloo ${ }^{2}$ and Sepehr Maghsoudloo ${ }^{3}$ \\ ${ }^{1}$ Department of Dentistry, Tufts University School of Dental Medicine, Boston, MA \\ ${ }^{2}$ Carr \& Associates Dental Office, Boston, MA \\ ${ }^{3}$ School of Dentistry, Centro Escolar University, Manila, Philippines
}

*Corresponding author: Bahram Ghassemia, Department of Dentistry, Tufts University School of Dental Medicine, Boston, MA

Received: 战 April 09, 2020

Published: 剕 June 11, 2020

Abbreviations: ECC: Early childhood caries; CDC: Center for Disease Control; NHANES: National Health and Nutrition Examination Surveys

\section{Introduction/Literature Review}

Early childhood caries (ECC) is an infectious disease affecting the primary dentition in infants and children younger than 6 years of age. Despite being a largely preventable condition, ECC remains a major public health problem in both developing and developed countries, with nearly 1.8 billion new cases diagnosed each year globally [1,2]. In the United States, Center for Disease Control and Prevention (CDC) reported a $15.2 \%$ increase in the prevalence of dental caries among the nation's youngest children, aged 2-5, comparing the findings of two National Health and Nutrition Examination Surveys, NHANES II, 1988-1994 and NHANES III, 1999-2004 [3,4]. A comprehensive epidemiological review of ECC showed that although the overall ECC prevalence varies from population to population, the socio-economically disadvantaged and minority groups are most at risk [5]. Numerous studies indicate that Hispanic and Native American children are among the high-risk North American populations [6]. ECC is multifactorial in its etiology and has been associated with a multitude of risk factors including inappropriate and prolonged bottle or breast feeding, frequent consumption of fermentable carbohydrates, and poor oral hygiene [6-8]. Vertical transmission of Streptococcus mutans from caregiver to child has been demonstrated [9]. A previous study has shown that $\mathrm{S}$. mutans or $\mathrm{S}$. sobrinus alone may not be the only indicators for high risk of caries, but the prevalence of S. oralis in saliva may be a risk factor for increased caries activity in severe ECC forms [10]. Being born preterm or small for gestational age [11], improper oral health practices, higher birth order, low fluoride in drinking water, poor saliva buffering capacity and behavioral factors are other risk factors $[12,13]$. The initial clinical presentation of ECC appears as white-spot lesions in the upper primary incisors along the margin of the gingiva [14]. Complete destruction of the crown can potentially follow if the disease continues [15]. The spread of caries to primary maxillary molars is seen in moderate cases and primary mandibular molars are involved in severe stages [16]. Greater probability of subsequent caries in both the primary [17] and the permanent18 dentitions is observed among the children who experienced caries as infants or toddlers [18]. Missing anterior teeth causes poor phonetics, unpleasant appearance, hardship in sociological and psychological adjustment, and nonefficient mastication [19]. Several studies have demonstrated the considerable negative impact ECC has on the health-related quality of life of children [20].

Maintaining the primary dentition in a healthy condition has innumerable benefits, therefore dental caries management in children is pivotal. Treatment options include the restoration or extraction of the carious teeth although the importance of preventative and preservative measures cannot be overstated. Construction of orthodontic appliances such as space maintainers or prosthetic management may be needed in some cases. The following case demonstrates the use of the Nance appliance and the Hyrax expander in addition to conventional orthodontic treatment over the course of nine years in order to obtain a Class I (Angle) canine and molar relationship in a child with severe early childhood caries. 


\section{Diagnosis}

The patient was a four-year-old Hispanic female that presented with the chief complaint of "missing frontal and some back teeth having difficulty chewing and speaking." No remarkable medical findings were noted. A facial evaluation revealed a symmetric face. She had a unilateral posterior cross bite with flush terminal deciduous molar relationship (Figure 1).
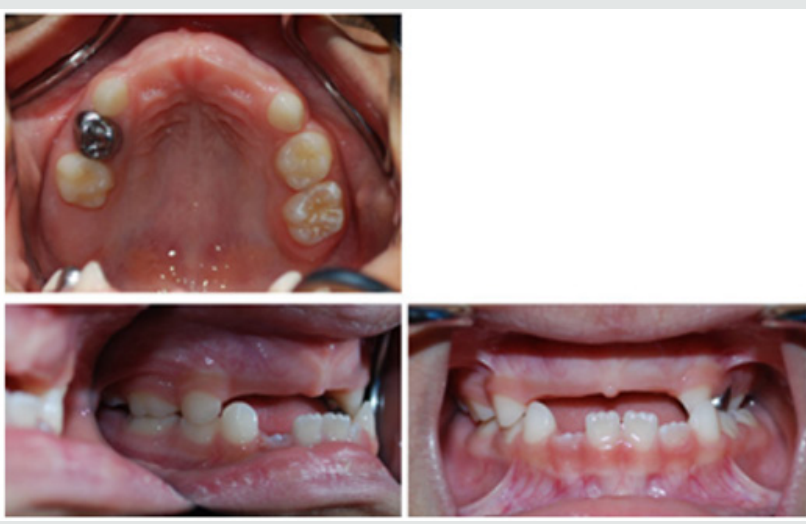

Figure 1.

\section{Treatment objectives}

The primary objectives of treatment were to maintain the space and replace the missing anterior teeth, to obtain a Class I (Angle) canine and molar relationship, with ideal overjet and overbite, and to improve facial esthetics. The complementary treatment objectives were to establish good functional and stable occlusion, to avoid crowding and lack of space of the upper incisors and premolars, while improving smile characteristics and eliminating lip incompetence.

\section{Treatment progress}

The treatment of choice was utilization of Nance appliance followed by conventional orthodontic treatment. After consultation with the patient and her parents, informed consent was obtained and treatment was begun. All components of the appliances were submitted to a dental laboratory for fabrication. Modified Nance appliances was fit on deciduous maxillary first molars at the age of four and a half Figure 2. The Hyrax appliance was fixed on teeth \#3 and \#14 when the patient was 11 years old Figure 3. The appliance's screw was turned twice a day until proper palatal expansion was achieved Figure 4. Treatment was followed by comprehensive orthodontic treatment lasting approximately 30 months Figure 5(A\&B). Immediate Essix retainers were placed at the deboning appointment Figure 6.
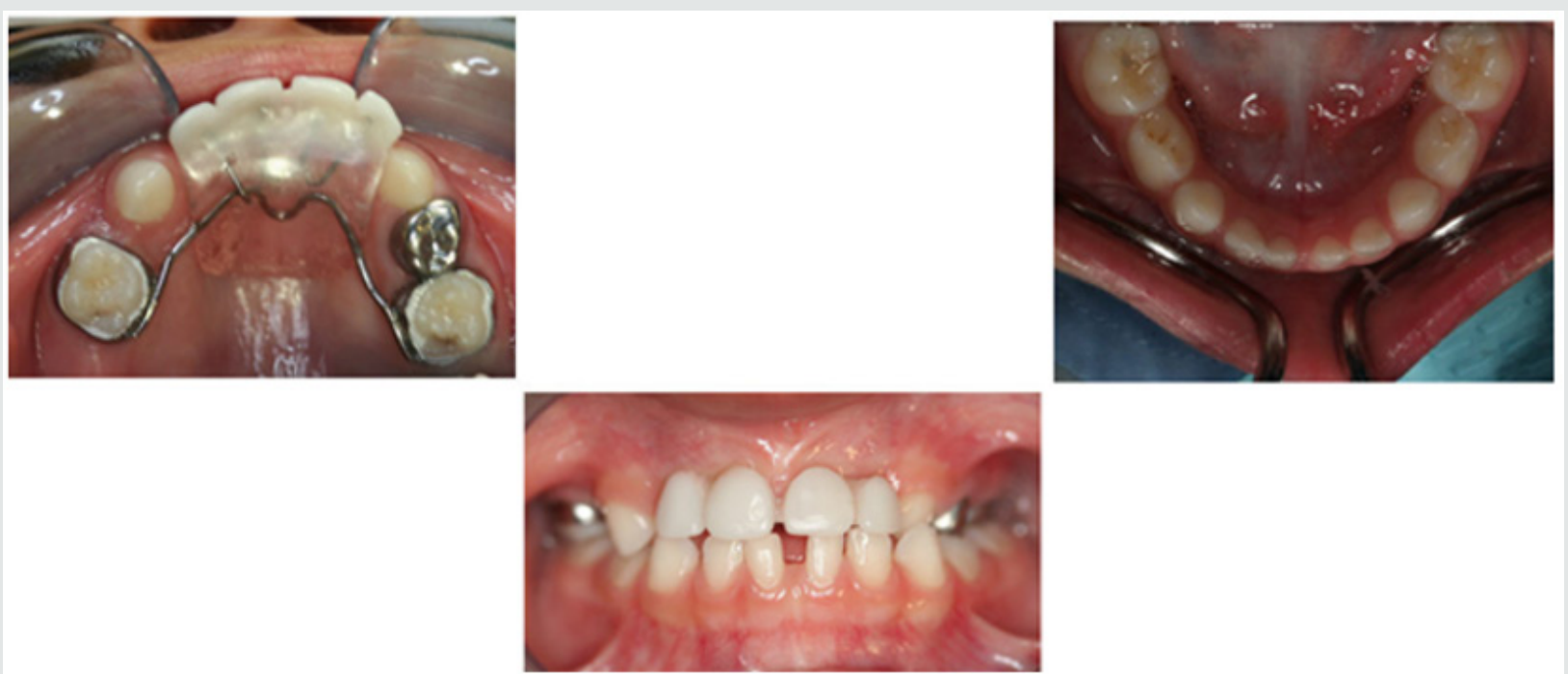

Figure 2. 


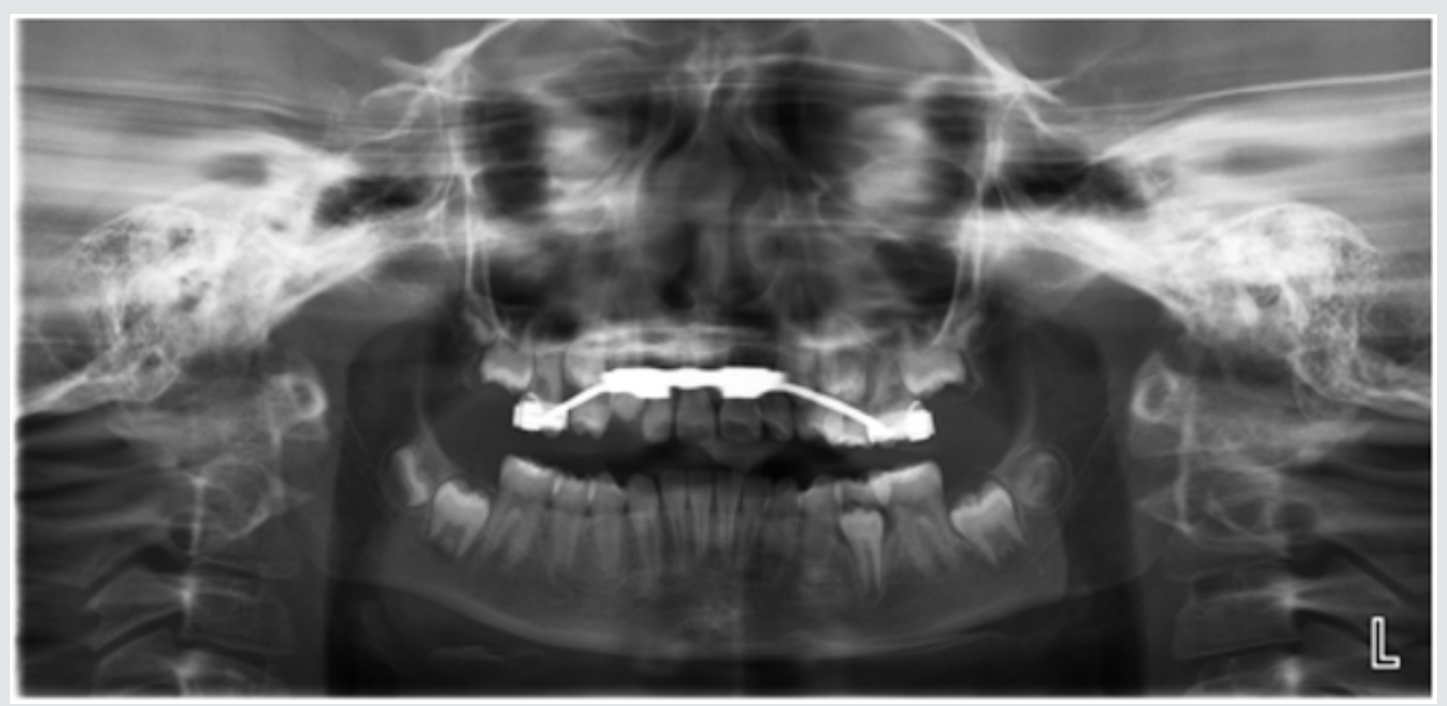

Figure 3.
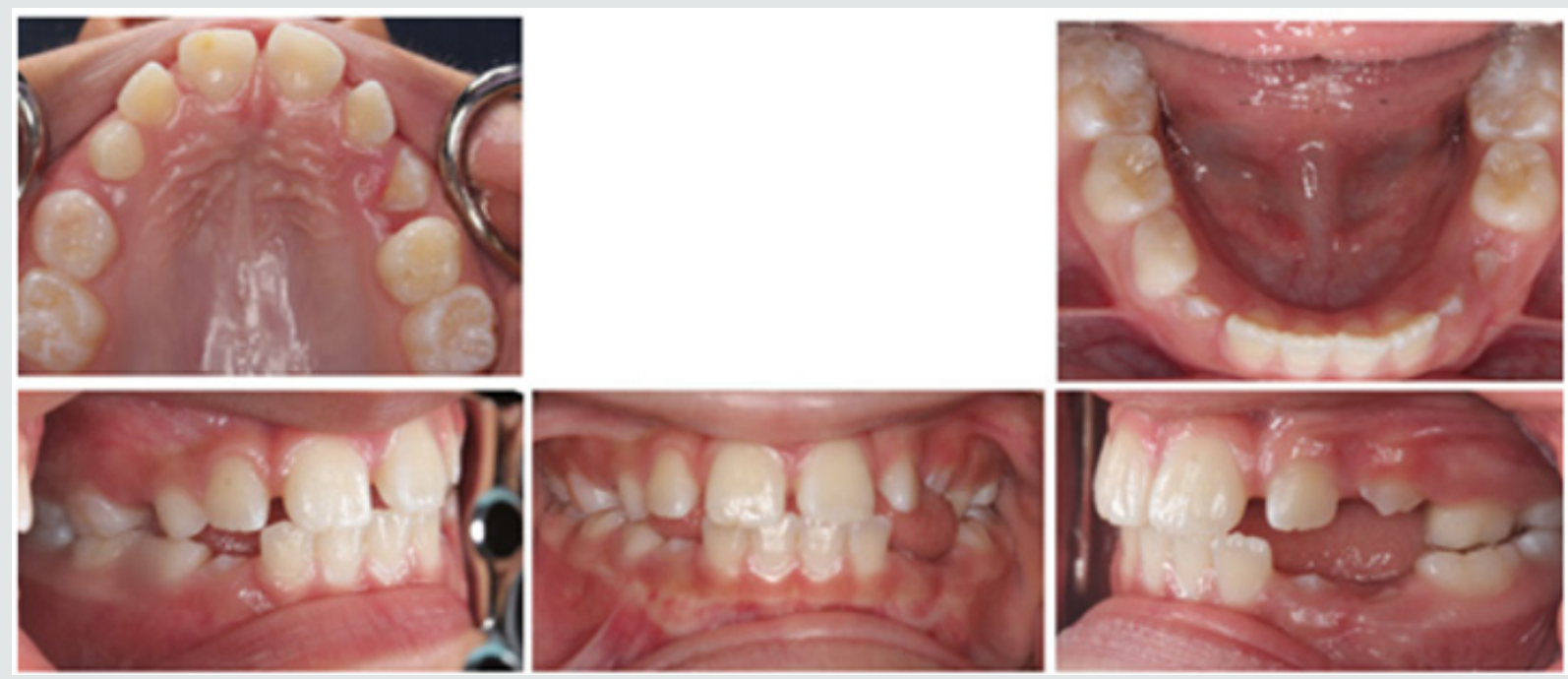

Figure 4 .

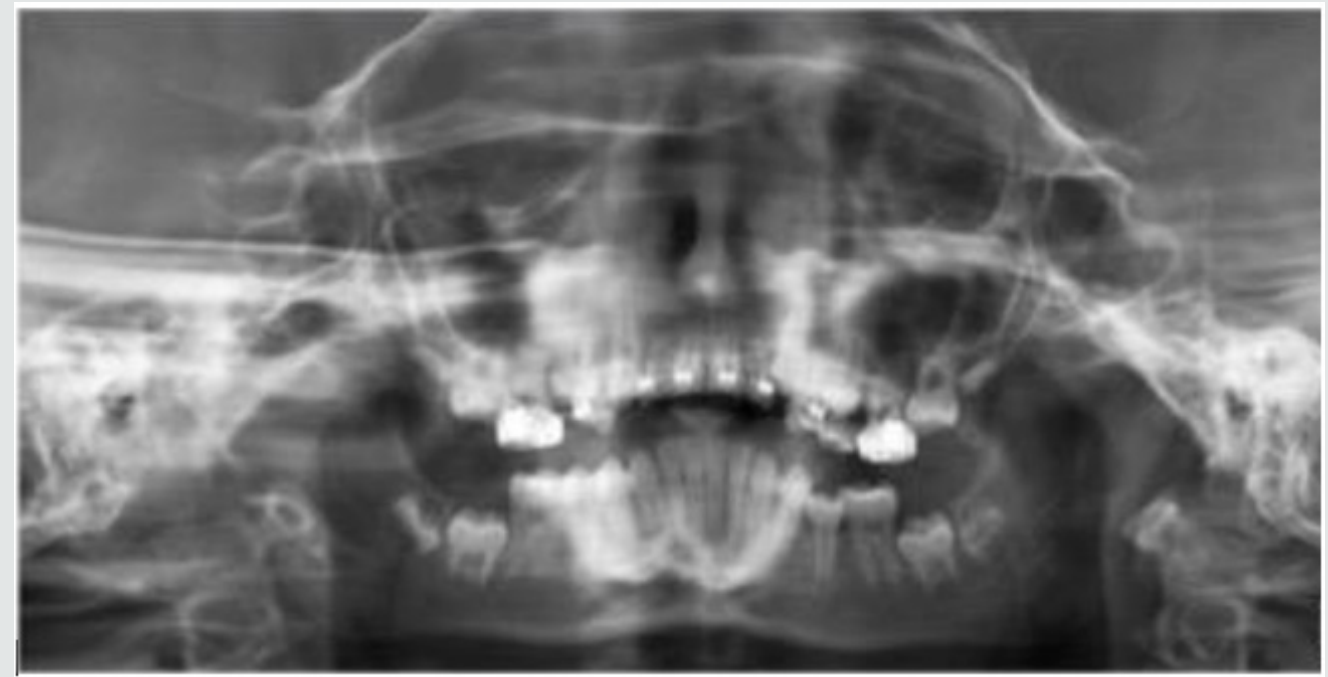

Figure 5a. 

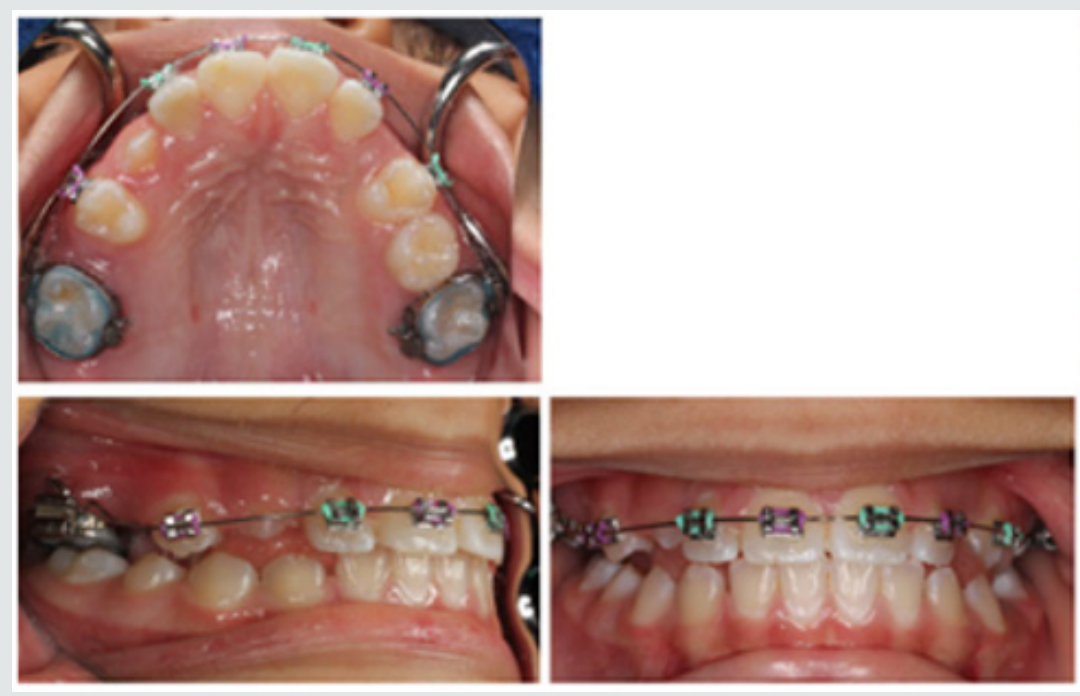

Figure 5b.

\section{Treatment Results}

Excellent facial and occlusal results were achieved with the nine-year treatment rendered. The most significant changes were the correction of the unilateral cross-bite malocclusion of the deciduous teeth and prevention of mesial shifting of posterior teeth in order to achieve both a molar and canine Class I (Angle) relationship of permanent dentition. The change in appraisal posttreatment also demonstrated normal occlusion with proper alignment of anterior teeth.

\section{Discussion}

Utilization of Nance appliance to avoid any further mesial shifting of posterior teeth was a pivotal part of the treatment. Reconstruction of anterior teeth helped the patient improve her speech and have a more desirable smile. Construction of a removable partial denture could be a different way to approach treatment in this case. It must be noted, however, that removable partial dentures have certain disadvantages such as presence of extra material in the mouth and increased speech difficulty for the child. They may be broken or lost easily and are ineffective to maintain space if not used properly. Since children are not competent to wear removable appliances, the ideal treatment option was a fixed non-functional appliance. The Hyrax appliance is a fixed functional appliance which was used during the treatment to correct the unilateral posterior cross bite and to expand the narrow maxillary arch. The alternative choice of appliance was the Haas expander. The latter option was not chosen due to requiring a more demanding oral hygiene regimen while offering the same treatment outcome as the Hyrax appliance in this case. Conventional orthodontic treatment was an inevitable part of the treatment plan to obtain Class I (Angle) canine and molar relationship, with ideal overjet and overbite which helps the patient to have proper tooth position in jaws, improve facial esthetics and reduce dental caries risk and future complications. Relying on conventional orthodontic treatment alone without the use of an expansion would not have been the proper approach since the Hyrax appliance helped with the expansion of the maxillary arch prior to the complete closure of the mid-palatal suture.

\section{References}

1. Çolak H, Dülgergil Ç, Dalli M, Hamidi M (2013) Early childhood caries update: A review of causes, diagnoses, and treatments. J Nat Sci Biol Med $4(1): 29-38$.

2. Xiao J, Grier A, Faustoferri RC, Alzoubi AL, Feng C, Liu Y, et al. (2018) Association between Oral Candida and Bacteriome in Children with Severe ECC. J Dent Res 97(13): 1468-1476.

3. Dye A, Tan S, Smith V (2007) Trends in oral health status: United States, 1988-1994 and 1999-2004. Vital Heal Stat Ser 11 Data from Natl Heal Surv 11: 248.

4. Beltrán Aguilar ED, Barker LK, Canto MT (2005) Surveillance for dental caries, dental sealants, tooth retention, edentulism, and enamel fluorosis-United States, 1988-1994 and 1999-2002. MMWR Surveill Summ Morb Mortal Wkly report Surveill Summ / CDC 54(3): 1-43.

5. Seow WK (2018) Early Childhood Caries. Pediatr Clin North Am 65(5): 941-954.

6. Berkowitz RJ (2003) Causes, treatment and prevention of early childhood caries: a microbiologic perspective. J Can Dent Assoc 69(5): 304-307.

7. Palmer CA, Kent R, Loo CY (2010) Diet and caries-associated bacteria in severe early childhood caries. J Dent Res 89(11): 1224-1229.

8. Caufield PW, Cutter GR, Dasanayake AP (1993) Initial Acquisition of Mutans Streptococci by Infants: Evidence for a Discrete Window of Infectivity. J Dent Res 72(1): 37-45.

9. Meriç E, Bolgül B, Duran N, Ay E (2020) Evaluation of oral streptococci in saliva of children with severe Early Childhood Caries and caries-free. Eur J Paediatr Dent 21(1): 13-17.

10. Boustedt K, Roswall J, Kjellberg E, Twetman S, Dahlgren J (2020) A prospective study of perinatal and metabolic risk factors for early childhood caries. Acta Paediatr. 
11. Anandakrishna L, Bhargav N, Hegde A, Chandra P, Gaviappa D, et al (2014) Problematic eating and its association with early childhood caries among 46-71-month-old children using Children's Eating Behavior Questionnaire (CEBQ): A cross sectional study. Indian J Dent Res 25(5): 602-606.

12. Dabawala S, Suprabha BS, Shenoy R, Rao A, Shah N (2017) Parenting style and oral health practices in early childhood caries: a case-control study. Int J Paediatr Dent 27(2): 135-144.

13. Kawashita Y, Kitamura M, Saito T (2011) Early childhood caries. Int J Dent.

14. Kagihara LE, Niederhauser VP, Stark M (2009) Assessment, management, and prevention of early childhood caries. J Am Acad Nurse Pract 21(1): $1-10$.

15. Anil S, Anand PS (2017) Early childhood caries: Prevalence, risk factors, and prevention. Front Pediatr 5: 157
16. Foster T, Perinpanayagam H, Pfaffenbach A, Certo M (2006) Recurrence of early childhood caries after comprehensive treatment with general anesthesia and follow-up. J Dent Child 73(1): 25-30.

17. Peretz B, Ram D, Azo E, Efrat Y (2000) Preschool caries as an indicator of future caries: a longitudinal study. Pediatr Dent 25(2):114-118.

18. Davies GN (1998) Early childhood caries--a synopsis. Community Dent Oral Epidemiol 26(1 Suppl): 106-116.

19. Singh N, Dubey N, Rathore M, Pandey P (2020) Impact of early childhood caries on quality of life: Child and parent perspectives. J Oral Biol Craniofacial Res 10(2): 83-86.

20. Ramos Jorge J, Pordeus IA, Ramos Jorge ML, Marques LS, Paiva SM (2014) Impact of untreated dental caries on quality of life of preschool children: different stages and activity. Community Dent Oral Epidemiol 42(4): 311-322

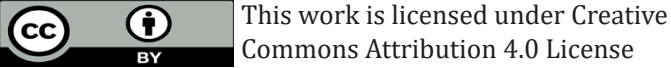

To Submit Your Article Click Here:

Submit Article

DOI: $10.32474 /$ IPDOAJ.2020.04.000181

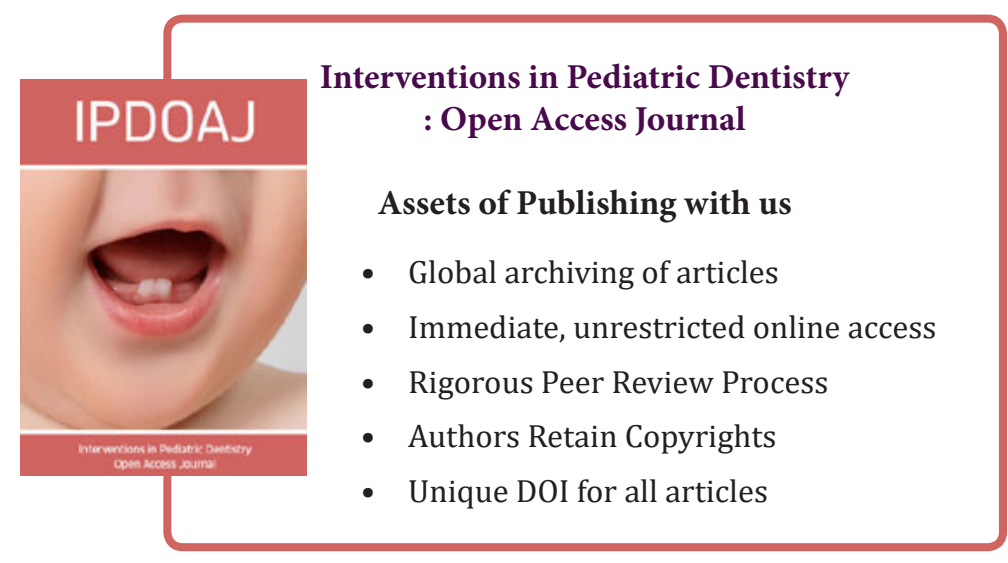

